\title{
Maternal Nrf2 and gluthathione-S-transferase polymorphisms do not modify associations of prenatal tobacco smoke exposure with asthma and lung function in school-aged children
}

\author{
A J Henderson, ${ }^{1}$ R B Newson, ${ }^{2}$ M Rose-Zerilli, ${ }^{3}$ S M Ring, ${ }^{4}$ J W Holloway, ${ }^{3}$ \\ S 0 Shaheen $^{2}$
}

- Additional tables are published online only. To view these files please visit the journal online (http://thorax.bmj. com)

\section{${ }^{1}$ Department of}

Community-based Medicine, University of Bristol, UK

${ }^{2}$ Respiratory Epidemiology and Public Health Group, National Heart and Lung Institute, Imperial College London, UK ${ }^{3}$ Respiratory Genetics Group, Division of Infection, Inflammation and Immunity and Division of Human Genetics, University of Southampton, UK ${ }^{4}$ Department of Social Medicine, University of Bristol, UK

Received 20 August 2009 Accepted 28 June 2010 Published Online First 30 August 2010

\begin{abstract}
Background Maternal smoking during pregnancy has detrimental effects on the respiratory health of infants and children. Polymorphisms of antioxidant genes including glutathione-S-transferases (GSTs) have been proposed as candidates for asthma and reduced lung function in children.
\end{abstract}

Methods Women enrolled in the Avon Longitudinal Study of Parents and Children reported smoking habits during pregnancy. Asthma status in their children was established at age 7.5 years from parental reports and lung function was measured by spirometry at age 8.5 years. Maternal and child DNA were genotyped for deletions of GSTM1 and GSTT1 and functional polymorphisms of GSTP1 and Nrf2 genes. Associations of prenatal tobacco smoke exposure with asthma and lung function in children were stratified by maternal genotype.

Results In 6606 children, maternal smoking during pregnancy was negatively associated with maximal mid expiratory flow $\left(\mathrm{FEF}_{25-75}\right)(-0.05 \mathrm{SD}$ units, $95 \% \mathrm{Cl}$ -0.07 to $-0.03, p<0.001)$. There was little evidence for interactions between maternal smoking and any maternal genotype considered on children's asthma or lung function. Maternal smoking was associated with reduced childhood $\mathrm{FEF}_{25-75}$ only in mother-child pairs $(n=1227)$ with both copies of GSTM1 deleted $(-0.08$ $\mathrm{SD}$ units, $95 \% \mathrm{Cl}-0.14$ to $-0.02, \mathrm{p}=0.01)$ or $(\mathrm{n}=2313)$ at least one copy of GSTT1 present $(-0.05$ SD units, $95 \% \mathrm{Cl}-0.09$ to $0, p=0.03$ ).

Conclusion This study confirms a detrimental effect of intrauterine tobacco smoke exposure on childhood lung function but no strong evidence of modification by maternal genotype for important antioxidant genes. Adverse effects of fetal exposure to tobacco smoke on the respiratory health of children may be mediated by pathways other than oxidative stress.

\section{INTRODUCTION}

Exposure to environmental tobacco smoke is associated with adverse respiratory outcomes in children and it is an exposure to which the developing lung is particularly susceptible. ${ }^{1}$ Although both prenatal and postnatal tobacco smoke exposure is detrimental to children's respiratory health, there is evidence to suggest that intrauterine exposure is more strongly associated with asthma and low lung function than passive exposure of children to secondhand smoke after birth. ${ }^{2-4}$ Studies of asymptomatic infants have reported decrements in lung function shortly after birth in infants exposed to maternal smoking during pregnancy, ${ }^{5} 6$ and it is possible that such deficits persist into later childhood $^{7}$ and adult life. ${ }^{9}$

The glutathione-S-transferases (GST) are a superfamily of enzymes that promote conjugation of reduced glutathione (L- $\gamma$-glutamyl-Lcysteinyl-glycine) with electrophilic substances and are thus important for the detoxification of reactive oxygen species involved in cellular processes of inflammation, such as tobacco smoke constituents. Glutathione is key to protecting the lungs from oxidative stress, as demonstrated by the high levels of glutathione present in human epithelial lining fluid. ${ }^{10}$ Two of the most relevant human GST isoenzymes, GSTT1 and GSTM1, exhibit copy number variation with a high proportion of the population carrying no copies of the genes, ${ }^{11}$ resulting in complete loss of enzyme function. Although GST deletions can be compensated by overlapping substrate affinities within the GST family, GSTM1 and GSTT1 deletions have consequences when the organism comes into contact with distinct chemicals. ${ }^{12}$ A further member of the GST family (GSTP1) is expressed in lung epithelium, ${ }^{13}$ and a functional polymorphism of this gene, substitution of isoleucine with valine at amino acid 105, is associated with altered enzyme activity. ${ }^{14}$ Genetic variants of GSTM1, P1 and T1 have been proposed as candidates for asthma ${ }^{15-18}$ and lung function growth. ${ }^{19}{ }^{20}$ Expression of GST enzymes is induced by Nuclear erythroid 2 p45-related factor 2 (Nrf2), a transcription factor that contributes to the induction of several protective enzymes during oxidative stress. Disruption of Nrf2 has been shown in mice to enhance both tobacco smoke-induced pulmonary injury $^{21}$ and susceptibility to severe airway inflammation and asthma. ${ }^{22}$

A number of studies have considered the interaction of child GST genotype with tobacco smoke exposure in utero ${ }^{23} 24$ in relation to adverse pulmonary outcomes in childhood. However, xenobiotics in the maternal circulation are capable of crossing the placenta. Alterations in maternal detoxification capacity could therefore expose the fetus to critical levels of toxic metabolites which could in part be compensated by the detoxification capability of the fetus. Murdsoka and colleagues have recently reported associations between 
maternal and infant GST polymorphisms in combination with prenatal tobacco smoke exposure on measures of lung function and airway responsiveness in infancy. ${ }^{25}$ We hypothesised that functional polymorphisms of GST and Nrf2 genes in the mother would modify the effects of prenatal tobacco smoke exposure on lung function and asthma in childhood. We also predicted that any detrimental effects of maternal genotype would be enhanced or attenuated by fetal genotypes associated with reduced or normal levels of enzyme activity, respectively. We investigated this in a large population-based birth cohort in which maternal and child DNA, mothers' smoking history collected during pregnancy and outcome measures on children were available.

\section{METHODS}

The Avon Longitudinal Study of Parents and Children (ALSPAC) is a population-based birth cohort that recruited 14541 pregnant women resident in Avon, UK with expected dates of delivery from 1 April 1991 to 31 December 1992. There were 14062 live born children, and 13988 of these children were alive at age 1 year and subsequently followed up. The cohort has been followed since birth with annual questionnaires and, since age 7 years, with objective measures in annual research clinics. The study protocol has been published previously ${ }^{26}$ and further details can be found at http://www.bris.ac.uk/alspac.

\section{Primary exposure}

Two self-report questionnaires sent to women during pregnancy at 18 weeks and 32 weeks gestation contained questions on current smoking habits. Responses were recorded on an ordinal categorical scale as follows: $0=$ no exposure; $1=$ passive exposure only (partner or other household member smokes); $2=$ smokes 1-9 cigarettes per day; $3=$ smokes $10-19$ cigarettes per day; $4=$ smokes $\geq 20$ cigarettes per day. The higher category reported at 18 or 32 weeks was used as the exposure variable for each subject in the analysis.

\section{Outcomes}

Current doctor-diagnosed asthma in the child was defined from parent-completed questionnaire at 7.5 years as reported doctordiagnosed asthma ever plus reported asthma or wheezing in the preceding 12 months. Lung function was measured by spirometry at age 8.5 years after withholding short-acting bronchodilators for at least $6 \mathrm{~h}$ and long-acting bronchodilators and theophyllines for at least $24 \mathrm{~h}$. The best of three reproducible flow-volume curves was used to measure forced expiratory volume in $1 \mathrm{~s}\left(\mathrm{FEV}_{1}\right)$ and maximal mid expiratory flow $\left(\mathrm{FEF}_{25-75}\right)$. These measurements were transformed to age, height and gender adjusted standard deviation units. ${ }^{27}$

\section{Genotyping}

Maternal DNA was extracted from whole blood and white cells collected during pregnancy. Single nucleotide polymorphisms (SNPs) in GSTP1 (G313A, Ile105Val, rs1695) and in the promoter region of Nrf2 (-684/-651 G/A, rs6706649) were determined by K-Biosciences Ltd (Hoddesdon, Herts, UK) using a competitive allele-specific PCR system (KASPar). GSTT1 and GSTM1 gene deletion genotyping was performed using a real-time PCR method described previously. ${ }^{28}$ Genotyping failure and error rates based on duplicate samples are shown in table E1 in the online supplement.

\section{Statistical analyses}

We measured the effect of maternal cigarette smoking on the outcomes using logistic regression models to estimate odds ratios for asthma and linear regression models to estimate arithmetic mean differences for lung function outcomes expressed as SD units $\left(\mathrm{FEV}_{1}\right.$ and $\left.\mathrm{FEF}_{25-75}\right)$. These effects were linear (or log linear) effects per category of the maternal smoking exposure. Huber variances were used to construct the confidence intervals.

To adjust effect estimates for confounding we constructed a smoking propensity score, which is a summary measure of 'exposure-proneness' of a subject and was based on selected confounder variables that have been associated with respiratory and atopic outcomes in the literature and which were not likely to be on the causal pathway (see table E2 in the online supplement). We therefore did not include birth anthropometry variables, gestational age and child's body mass index (BMI) at 7 years. Data on confounders were collected from questionnaires sent to the child's mother during pregnancy and at 8 months after birth. These included assessment of postnatal tobacco smoke exposure, which was categorised as yes/no in response to a question about exposure to smokers in the household on weekend days. Propensity scores have been described previously for adjustment of ordinal discrete exposures, analogous to the smoking exposure categories that were considered in this study. ${ }^{29}$ A further description of propensity scores is given in the online supplement.

Distributions of allele frequencies for each polymorphism in mothers and children were tested for deviation from Hardy-Weinberg equilibrium. ${ }^{30}$ Adjusted effects of maternal smoking on the primary outcomes were then stratified by maternal genotype. To test for gene-smoking interactions, we used a Wald $\chi^{2}$ or F-test for heterogeneity between the smoking effects in the genotype strata. Finally, we examined associations between propensity-adjusted maternal smoking and outcomes stratified by combinations of maternal/child null GSTM1/T1 genotypes.

\section{RESULTS}

Antenatal smoking status was obtained in 13384 women who reported smoking habits on at least one occasion during pregnancy. Of these, 5467 (40.8\%) were unexposed, 4285 (32\%) had passive exposure only, 1234 (9.2\%) smoked 1-9 cigarettes/day, 1606 (12\%) smoked 10-19/day and 792 (5.9\%) reported smoking $\geq 20 /$ day. Maternal and child GST and Nrf2 genotype frequencies did not deviate significantly from Hardy-Weinberg equilibrium.

Data on asthma were available for 8002 children at age 7.5 years and lung function measures were available for 6606 children aged 8.5 years. In the latter group the smoking exposure status of mothers during pregnancy was as follows: 3118 (47.2\%) unexposed, 2213 (33.5\%) passive only, 526 (8\%) 1-9/ day, 517 (7.8\%) 10-19/day and $232(3.5 \%) \geq 20 /$ day. Numbers of subjects varied according to combinations of exposures and outcomes with availability of genetic data. Actual numbers with data available are shown in the tables. Baseline demographics of the cohort with smoking data and those with asthma and lung function outcomes at follow-up are shown in table E3 in the online supplement. Fewer women in the higher smoking categories attended for follow-up compared with those who were lost to follow-up.

Table 1 shows the proportions of children with asthma and mean $\mathrm{FEV}_{1}$ and $\mathrm{FEF}_{25-75}$ at 8 years according to maternal smoking status during pregnancy. Although unadjusted estimates suggested a positive association between maternal smoking and asthma in children, the effect was substantially attenuated by adjustment for smoking propensity (table 2). 
Table 1 Prevalence of asthma and mean lung function according to level of maternal smoking during pregnancy

\begin{tabular}{|c|c|c|c|c|c|c|}
\hline & \multicolumn{2}{|c|}{ Asthma } & \multicolumn{2}{|l|}{ FEV $_{1}$} & \multicolumn{2}{|c|}{$\mathrm{FEF}_{25-75}$} \\
\hline & $\mathbf{N}$ & $\begin{array}{l}\text { Prevalence } \\
(\%)\end{array}$ & $\mathbf{N}$ & $\begin{array}{l}\text { Mean } \\
\text { (SD score) }\end{array}$ & $\mathbf{N}$ & $\begin{array}{l}\text { Mean } \\
\text { (SD score) }\end{array}$ \\
\hline \multicolumn{7}{|c|}{ Maternal smoking status } \\
\hline $\begin{array}{l}\text { Not } \\
\text { exposed }\end{array}$ & 3720 & 11.3 & 3077 & 0.02 & 3118 & 0.03 \\
\hline Passive only & 2609 & 12.2 & 2163 & 0.00 & 2213 & 0.03 \\
\hline $1-9 /$ day & 656 & 13.6 & 521 & 0.02 & 526 & -0.03 \\
\hline $10-19 /$ day & 721 & 15.0 & 513 & -0.04 & 517 & -0.19 \\
\hline$\geq 20 /$ day & 296 & 14.5 & 230 & -0.10 & 232 & -0.14 \\
\hline
\end{tabular}

$\mathrm{FEF}_{25-75}$, maximal mid expiratory flow; $\mathrm{FEV}_{1}$, forced expiratory volume in $1 \mathrm{~s}$.

There was a negative association of maternal smoking with $\mathrm{FEF}_{25-75}$ with a small decrement $(-0.05 \mathrm{SD}$; equivalent to approximately $-26 \mathrm{ml} / \mathrm{s}$ ) for each increase in maternal smoking category that remained after propensity adjustment.

The associations of maternal and child genotypes with each of the primary outcomes is show in tables E4-E6 in the online supplement. There was no strong evidence for gene-only associations of either maternal or child genotype with asthma or lung function.

Tables 3 and 4 show the associations between maternal smoking category and asthma and $\mathrm{FEF}_{25-75}$ respectively stratified by maternal genotype. There was no evidence for interactions between tobacco smoke exposure and maternal genotype on childhood asthma. For $\mathrm{FEF}_{25-75}$ there appeared to be a negative association with smoking when the GSTT1 gene was present but, when analysed by copy number variation, this effect was confined to those with one copy of the gene rather than two or none, with weak evidence of an interaction. In contrast, $\mathrm{FEF}_{25-75}$ was lower when GSTM1 was absent but there was no evidence to support a statistical interaction between tobacco smoke exposure and genotype on this outcome. There was no evidence to suggest that the relation between prenatal tobacco smoke exposure and $\mathrm{FEV}_{1}$ was modified by GST or Nrf2 genetic variants (data not shown).

Table 5 shows the associations of maternal smoking with asthma and $\mathrm{FEF}_{25-75}$ stratified by combinations of maternal and child GSTM1 deletions. This demonstrates evidence for an effect of maternal smoking on asthma when both mother and child have at least one copy of the GSTM1 gene present (OR 1.23, $95 \%$ CI 1.02 to $1.48, p=0.03$ ). In contrast, a convincing deficit in $\mathrm{FEF}_{25-75}$ was restricted to mothers and children who both had the null genotype $(0.08 \mathrm{SD}, \mathrm{p}=0.01)$. The results of similar analyses for GSTT1 genotypes are shown in table 6. In this case, the presence of at least one copy of GSTT1 in both mother and child was associated with reduced $\mathrm{FEF}_{25-75}(0.05 \mathrm{SD}, \mathrm{p}=0.03$ ).

\section{DISCUSSION}

Our results confirm previous reports ${ }^{2}{ }^{4}$ that intrauterine tobacco smoke exposure is associated with lower maximal mid expira- tory flow in childhood. However, we did not find evidence of an independent effect of maternal smoking during pregnancy on reported asthma in children. Although there was a positive association on univariable analysis, this was attenuated almost completely by adjustment for smoking propensity, suggesting that uncontrolled or residual confounding may have contributed to previous reports of an association with childhood asthma. ${ }^{3} 31$

When we stratified by maternal genotype, the detrimental effects of maternal smoking on mid expiratory flows appeared to be greatest in the presence and absence of GSTT1 and GSTM1, respectively. Furthermore, an effect of maternal smoking on asthma risk was only apparent when GSTM1 was present in both mother and child. However, on formal statistical testing for interaction we did not find convincing evidence for effect modification of maternal smoking effects by these genotypes.

\section{Results in the context of other literature}

Although our results did not support a major role for maternal Nrf2 or GST genotypes in modifying the association of prenatal smoke exposure with asthma or lung function in this population, these polymorphisms were relevant genetic targets in relation to tobacco smoke exposure for several reasons. Smoking by pregnant women has been associated with markers of fetal oxidative stress in cord blood ${ }^{32}$ and urine $e^{33}$ of newborn infants. Nrf2 is a transcription factor that is involved in the induction of many antioxidant genes and is critical for the regulation of airway inflammation associated with exposure to particulates. ${ }^{34}$ Disruption of the Nrf2 pathway has been associated with eosinophilic airway inflammation and a severe asthma phenotype in a mouse model. ${ }^{22}$ However, we found no evidence for gene main effects on asthma and lung function in children or evidence for interactions with maternal smoking on these outcomes. Given its central role as a master regulator of antioxidant genes, our findings suggest that the detrimental effects of maternal smoking on fetal airway growth may not be mediated primarily through oxidative stress.

The GST enzymes have major roles in detoxification of oxidative stress associated with exposure to tobacco smoke metabolites. ${ }^{35}$ Deletion of GSTM1 and GSTT1 genes in mothers has been reported to modify fetal oxidative stress. ${ }^{33} 36$ There is some evidence to support GST polymorphisms as asthma candidates, but results between studies have not been consistent ${ }^{15-18}$ and a recent meta-analysis did not support a substantial effect of these genes on asthma risk. ${ }^{37}$ Inconsistent associations between these genes and asthma in different populations could be attributed to between-population variations in environmental exposures. There have now been several reports of interactions between GST polymorphisms and oxidant exposures including ozone ${ }^{38} 39$ and tobacco smoke 24041 influencing the occurrence of asthma and respiratory symptoms in children. These reports have concentrated on children's genotypes modifying disease risk associated with exposures, including those occurring in the prenatal period.

Table 2 Unadjusted and adjusted associations of maternal smoking (per category effects) with asthma and lung function in children

\begin{tabular}{|c|c|c|c|c|c|c|c|}
\hline \multicolumn{8}{|l|}{ Odds ratios } \\
\hline Asthma & 8002 & 1.10 & (1.04 to 1.16$)$ & 0.002 & 1.03 & (0.96 to 1.11$)$ & 0.4 \\
\hline $\mathrm{FEV}_{1} \mathrm{SDS}$ & 6504 & -0.02 & $(-0.04$ to 0.00$)$ & 0.07 & -0.00 & ( -0.03 to 0.02$)$ & 0.9 \\
\hline $\mathrm{FEF}_{25-75} \mathrm{SDS}$ & 6606 & -0.05 & $(-0.07$ to -0.03$)$ & $5.2 \times 10^{-6}$ & -0.05 & $(-0.08$ to -0.02$)$ & 0.0003 \\
\hline
\end{tabular}

*Adjusted for propensity score (see methods for details).

$\mathrm{AM}$, arithmetic mean; $\mathrm{FEF}_{25-75}$, maximal mid expiratory flow; $\mathrm{FEV}_{1}$, forced expiratory volume in $1 \mathrm{~s}$. 
Table 3 Associations between maternal smoking and children's asthma stratified by maternal Nrf2 and GST genotype

\begin{tabular}{|c|c|c|c|c|c|}
\hline & $\mathbf{N}$ & Cases (\%) & $\mathbf{O} \mathbf{R}^{*}$ & $(95 \% \mathrm{CI})$ & p Value \\
\hline \multicolumn{6}{|l|}{ Nrf2 } \\
\hline C:C & 3788 & $470(12.4)$ & 1.03 & (0.93 to 1.14$)$ & 0.58 \\
\hline $\mathrm{T}: \mathrm{C}$ & 1068 & $151(13.1)$ & 1.04 & (0.85 to 1.26$)$ & 0.72 \\
\hline $\mathrm{T}: \mathrm{T}$ & 78 & $10(12.8)$ & 1.51 & (0.33 to 6.92$)$ & 0.59 \\
\hline Interaction & 4934 & $631(12.8)$ & & & 0.92 \\
\hline \multicolumn{6}{|l|}{ GSTT1 } \\
\hline Present & 3871 & $494(12.8)$ & 1.05 & (0.95 to 1.16$)$ & 0.38 \\
\hline Absent & 783 & $104(13.3)$ & 0.99 & (0.80 to 1.23$)$ & 0.95 \\
\hline Interaction & 4654 & $598(12.8)$ & & & 0.67 \\
\hline \multicolumn{6}{|l|}{ Copy number } \\
\hline 2 & 1232 & $152(12.3)$ & 1.11 & (0.93 to 1.34$)$ & 0.24 \\
\hline 1 & 1973 & $259(13.1)$ & 1.06 & (0.92 to 1.22 ) & 0.43 \\
\hline 0 & 783 & $104(13.3)$ & 0.99 & $(0.80$ to 1.23$)$ & 0.95 \\
\hline Interaction & 3988 & $515(12.9)$ & & & 0.72 \\
\hline \multicolumn{6}{|l|}{ GSTM1 } \\
\hline Present & 2209 & $265(12.0)$ & 1.06 & (0.93 to 1.22$)$ & 0.37 \\
\hline Absent & 2483 & $338(13.6)$ & 1.00 & (0.89 to 1.14$)$ & 0.95 \\
\hline Interaction & 4692 & $603(12.9)$ & & & 0.53 \\
\hline \multicolumn{6}{|l|}{ Copy number } \\
\hline 2 & 311 & 45 (14.5) & 1.18 & (0.84 to 1.66$)$ & 0.35 \\
\hline 1 & 1723 & $200(11.6)$ & 1.06 & (0.91 to 1.25$)$ & 0.43 \\
\hline 0 & 2483 & $338(13.6)$ & 1.00 & (0.89 to 1.14 ) & 0.95 \\
\hline Interaction & 4517 & $583(12.9)$ & & & 0.65 \\
\hline \multicolumn{6}{|l|}{ GSTP1 } \\
\hline$A: A$ & 2082 & $250(12.0)$ & 1.02 & (0.88 to 1.18 ) & 0.81 \\
\hline $\mathrm{G}: \mathrm{A}$ & 2254 & $298(13.2)$ & 1.03 & (0.91 to 1.18 ) & 0.61 \\
\hline G:G & 597 & $84(14.1)$ & 1.16 & (0.89 to 1.49 ) & 0.27 \\
\hline Interaction & 4933 & $632(12.8)$ & & & 0.72 \\
\hline
\end{tabular}

${ }^{*}$ Adjusted for smoking propensity (see methods for details).

However, the detoxification of tobacco smoke metabolites by pregnant smokers is likely to affect the oxidant load experienced by the fetus. Carroll et al have previously reported in a small study that the minor allele of GSTP1 Ile105Val in mothers was associated with higher $\mathrm{FEV}_{1}$ in their children with asthma, ${ }^{42}$ and Murdzoska and colleagues recently reported positive associations of lung function (maximal flow at functional residual capacity, $\mathrm{V}^{\prime} \max _{\mathrm{FRC}}$ ) during the first year with maternal GSTP1 Val/Val or Val/Ile compared with homozygous Ile alleles. ${ }^{25}$ We did not find evidence for a negative association between maternal GSTP1 Ile105 allele and children's lung function in our cohort. In infants exposed to prenatal tobacco smoke, Murdzoska and coworkers reported higher $V^{\prime} \max _{\mathrm{FRC}}$ associated with one or more copies of the GSTT1 gene in mothers and/or infants. ${ }^{25}$ In contrast, our results showed a lower $\mathrm{FEF}_{25-75}$ in later childhood in smokeexposed children of mothers with a non-null GSTT1 genotype, but there was unconvincing evidence of an interaction and no gene copy dose-response relationship. This result is puzzling as a priori we would have expected the greatest effects of smoking to be in the GSTT1-null individuals, given the antioxidant function of the gene. For the GSTM1-null allele there was little evidence of an interaction with smoke exposure in association with $\mathrm{FEF}_{25-75}$,
Table 4 Associations between maternal smoking and children's $\mathrm{FEF}_{25-75}$ stratified by maternal Nrf2 and GST genotype

\begin{tabular}{|c|c|c|c|c|}
\hline & $\mathbf{N}$ & AM difference* & (95\% Cl) & p Value \\
\hline \multicolumn{5}{|l|}{ Nrf2 } \\
\hline $\mathrm{C:C}$ & 3174 & -0.05 & $(-0.09$ to -0.01$)$ & 0.015 \\
\hline $\mathrm{T}: \mathrm{C}$ & 894 & -0.01 & $(-0.10$ to 0.07$)$ & 0.75 \\
\hline $\mathrm{T}: \mathrm{T}$ & 67 & -0.16 & $(-0.55$ to 0.22$)$ & 0.4 \\
\hline Interaction & 4135 & & & 0.62 \\
\hline \multicolumn{5}{|l|}{ GSTT1 } \\
\hline Present & 3235 & -0.06 & $(-0.09$ to -0.02$)$ & 0.004 \\
\hline Absent & 649 & 0.03 & $(-0.06$ to 0.12$)$ & 0.57 \\
\hline Interaction & 3884 & & & 0.1 \\
\hline \multicolumn{5}{|c|}{ Copy number } \\
\hline 2 & 1025 & -0.01 & $(-0.07$ to 0.06$)$ & 0.84 \\
\hline 1 & 1649 & -0.09 & $(-0.14$ to -0.03$)$ & 0.002 \\
\hline 0 & 649 & 0.03 & $(-0.06$ to 0.12$)$ & 0.57 \\
\hline Interaction & 3323 & & & 0.06 \\
\hline \multicolumn{5}{|l|}{ GSTM1 } \\
\hline Present & 1851 & -0.02 & $(-0.07$ to 0.03$)$ & 0.46 \\
\hline Absent & 2062 & -0.06 & $(-0.10$ to -0.01$)$ & 0.02 \\
\hline Interaction & 3913 & & & 0.31 \\
\hline \multicolumn{5}{|c|}{ Copy number } \\
\hline 2 & 260 & 0.08 & $(-0.08$ to 0.24$)$ & 0.31 \\
\hline 1 & 1442 & -0.03 & $(-0.09$ to 0.03$)$ & 0.32 \\
\hline 0 & 2062 & -0.06 & $(-0.10$ to -0.01$)$ & 0.02 \\
\hline Interaction & 3764 & & & 0.25 \\
\hline \multicolumn{5}{|l|}{ GSTP1 } \\
\hline$A: A$ & 1728 & -0.05 & $(-0.11$ to 0.01$)$ & 0.09 \\
\hline $\mathrm{G}: \mathrm{A}$ & 1894 & -0.05 & $(-0.10$ to 0.00$)$ & 0.07 \\
\hline G:G & 519 & -0.04 & $(-0.14$ to 0.05$)$ & 0.38 \\
\hline Interaction & 4141 & & & 0.99 \\
\hline
\end{tabular}

*Arithmetic mean difference of standard deviations (SDS) between categories, adjusted for smoking propensity (see methods for details).

$\mathrm{AM}$, arithmetic mean; $\mathrm{FEF}_{25-75}$, maximal mid expiratory flow.

although this measure was lowest when the mother was homozygous for the null variant. This effect appeared to be modified by the child's genotype, with GSTM1-null homozygosity in both mother and child being associated with lowest $\mathrm{FEF}_{25-75}$ in tobacco smoke-exposed children. Gilliland and colleagues reported decrements in lung function growth in childhood associated with the GSTM1-null genotype in children, ${ }^{20}$ so it is possible that the child's genotype is more important in determining respiratory outcomes during later childhood than in infancy, which may explain some of the discrepancies between our findings and those of Murdzoska and others.

\section{Strengths and limitations of this study}

We had access to a large population-based cohort with recruitment in pregnancy, thus allowing collection of data on the principal exposure prior to the birth of the child and avoiding recall bias. Two particular strengths were availability of maternal DNA, allowing us to investigate the effects of genes involved in the detoxification of tobacco smoke by the mother, and copy number variation of the GSTM1 and GSTT1 deletions. Few previous studies have considered maternal genotype in

Table 5 Associations between maternal smoking and children's asthma and FEF $_{25-75}$ according to maternal and child GSTM1-null genotypes

\begin{tabular}{|c|c|c|c|c|c|c|c|c|c|c|}
\hline \multicolumn{2}{|l|}{ GSTM1 } & \multicolumn{5}{|c|}{ Asthma } & \multicolumn{4}{|c|}{$\mathrm{FEF}_{25-75}$} \\
\hline Mother & Child & $\mathbf{N}$ & Cases (\%) & OR & (95\% CI) & p Value & $\mathbf{N}$ & AM difference & $(95 \% \mathrm{CI})$ & p Value \\
\hline+ & + & 1137 & 137 (12.0) & 1.23 & (1.02 to 1.48$)$ & 0.03 & 999 & 0.02 & $(-0.05$ to 0.09$)$ & 0.63 \\
\hline+ & - & 525 & 60 (11.4) & 0.77 & (0.54 to 1.08 ) & 0.13 & 477 & -0.04 & $(-0.13$ to 0.05$)$ & 0.36 \\
\hline- & + & 513 & $64(12.5)$ & 1.05 & (0.79 to 1.39$)$ & 0.76 & 456 & 0.03 & $(-0.08$ to 0.14$)$ & 0.58 \\
\hline- & - & 1396 & $196(14.0)$ & 1.05 & (0.88 to 1.24$)$ & 0.6 & 1227 & -0.08 & $(-0.14$ to -0.02$)$ & 0.012 \\
\hline
\end{tabular}

$\mathrm{AM}$, arithmetic mean; $\mathrm{FEF}_{25-75}$, maximal mid expiratory flow; +, one or more copies of GSTM1; - homozygous deletion of GSTM1. 
Table 6 Associations between maternal smoking and children's asthma and $\mathrm{FEF}_{25-75}$ according to maternal and child GSTT1-null genotypes

\begin{tabular}{|c|c|c|c|c|c|c|c|c|c|c|}
\hline \multicolumn{2}{|l|}{ GSTT1 } & \multicolumn{5}{|c|}{ Asthma } & \multicolumn{4}{|c|}{$\mathrm{FEF}_{25-75}$} \\
\hline Mother & Child & $\overline{\mathbf{N}}$ & Cases (\%) & $\mathbf{O R}$ & (95\% CI) & $\overline{\text { p Value }}$ & $\overline{\mathbf{N}}$ & AM difference & (95\% CI) & p Value \\
\hline+ & + & 2577 & 331 (12.8) & 1.05 & (0.93 to 1.19 ) & 0.43 & 2313 & -0.05 & $(-0.09$ to -0.00$)$ & 0.03 \\
\hline+ & - & 349 & $40(11.5)$ & 1.15 & (0.77 to 1.71 ) & 0.48 & 296 & 0.04 & $(-0.09$ to 0.18$)$ & 0.51 \\
\hline- & + & 340 & $47(13.8)$ & 1.19 & (0.85 to 1.68 ) & 0.31 & 313 & -0.02 & $(-0.15$ to 0.11$)$ & 0.77 \\
\hline - & - & 242 & $29(12.0)$ & 0.70 & (0.45 to 1.10$)$ & 0.13 & 202 & 0.00 & $(-0.17$ to 0.18$)$ & 0.96 \\
\hline
\end{tabular}

$\mathrm{AM}$, arithmetic mean; $\mathrm{FEF}_{25-75}$, maximal mid expiratory flow; +, one or more copies of GSTT1; -homozygous deletion of GSTT1.

relation to asthma and lung function in childhood and our study had greater power than previous smaller studies to detect gene-environment interactions. There is recent evidence that maternal GSTM1 and GSTT1 polymorphisms may influence the association between maternal smoking and adverse pregnancy outcomes such as low birth weight. ${ }^{43}$ One of the advantages of considering maternal genotype is that it provides a potential tool for segregating intrauterine effects from postnatal exposures as maternal genotype cannot directly influence the response of the infant to the latter, although fetal genotype may influence the response to transplacental carriage of toxic metabolites.

The limitations of our study include reliance on reported asthma outcomes, although we also considered objectively measured outcomes in this study, and lack of biological markers of tobacco smoke exposure in mothers or infants. Although there are discrepancies between measures of nicotine metabolites such as cotinine and self-reported smoking habits, the latter have been consistently shown to have strong dose-dependent associations with relevant health outcomes. ${ }^{44}$ In common with other large population-based studies, there was considerable loss to follow-up or incomplete data in a large proportion of the sample. Loss to follow-up was associated with greater exposure to tobacco smoke during pregnancy and, although genotype is likely to be random with respect to lifestyle or loss to follow-up, it might be speculated that an interaction between genotype and exposure might have been revealed in a more highly exposed sample and our effect estimates are conservative. However, our population did contain a sizeable number of women who reported high smoking rates and post hoc analysis did not suggest non-linearity of effects across smoking categories. Although our study is large, the number of asthma cases in each cell when stratified by maternal genotype was small for less common alleles. This inevitably limits the power of our study to detect modest interactions of tobacco smoke exposure with genotype, but we consider it unlikely that we have overlooked a sizeable effect.

\section{CONCLUSIONS}

This study confirms previously reported detrimental effects of intrauterine tobacco smoke exposure on the respiratory health of children, particularly on measures of small airway function. However, we did not find strong evidence of modification of this effect by maternal genotype for a group of enzymes that are fundamental to detoxification of a range of xenobiotics. Other genes or metabolic pathways may be implicated in the susceptibility of infants to the adverse effects of tobacco smoke. For example, the recently described association of $17 \mathrm{q} 21$ variants with early onset asthma was stronger in children of smoking mothers, ${ }^{45}$ and interactions have been reported between tobacco smoke exposure and ADAM33 polymorphisms in the development of lung function and bronchial responsiveness in children. ${ }^{46}$

Acknowledgements We are extremely grateful to all the families who took part in this study, the midwives for their help in recruiting them, and the whole Avon Longitudinal Study of Parents and Children (ALSPAC) team which includes interviewers, computer and laboratory technicians, clerical workers, research scientists, volunteers, managers, receptionists and nurses.

Funding The UK Medical Research Council, the Wellcome Trust and the University of Bristol provide core support for the Avon Longitudinal Study of Parents and Children. This research was specifically funded by the British Lung Foundation. SOS is an Asthma UK Senior Research Fellow.

\section{Competing interests None.}

Ethics approval This study was conducted with the approval of the Avon Longitudinal Study of Parents and Children Ethics and Law Committee (IRB 00003312) and local research ethics committee, University Hospitals Bristol NHS Trust.

Contributors AJH and SOS conceived the study; RBN performed the statistica analyses; SMR, MR-Z and JWH conducted the genetic aspects of the study; SOS, AJH and JWH obtained the funding; all authors contributed to interpretation of the findings and writing the manuscript. AJH and SOS are guarantors for the contents of the paper.

Provenance and peer review Not commissioned; externally peer reviewed.

\section{REFERENCES}

1. Wang L, Pinkerton KE. Detrimental effects of tobacco smoke exposure during development on postnatal lung function and asthma. Birth Defects Res C Embryo Today 2008;84:54-60.

2. Cook DG, Strachan DP, Carey IM. Health effects of passive smoking. 9. Parental smoking and spirometric indices in children. Thorax 1998;53:884-93.

3. Gilliland FD, Li YF, Peters JM. Effects of maternal smoking during pregnancy and environmental tobacco smoke on asthma and wheezing in children. Am J Respir Crit Care Med 2001;163:429-36.

4. Gilliland FD, Berhane K, McConnell R, et al. Maternal smoking during pregnancy, environmental tobacco smoke exposure and childhood lung function. Thorax 2000;55:271-6.

5. Stick SM, Burton PR, Gurrin L, et al. Effects of maternal smoking during pregnancy and a family history of asthma on respiratory function in newborn infants. Lancet 1996;348:1060-4.

6. Dezateux C, Stocks J, Dundas I, et al. Impaired airway function and wheezing in infancy: the influence of maternal smoking and a genetic predisposition to asthma. Am J Respir Crit Care Med 1999;159:403-10.

7. Gilliland FD, Berhane K, Li YF, et al. Effects of early onset asthma and in utero exposure to maternal smoking on childhood lung function. Am J Respir Crit Care Med 2003;167:917-24.

8. Cunningham J, Dockery DW, Speizer FE. Maternal smoking during pregnancy as a predictor of lung function in children. Am J Epidemiol 1994;139:1139-52.

9. Upton MN, Smith GD, McConnachie A, et al. Maternal and personal cigarette smoking synergize to increase airflow limitation in adults. Am J Respir Crit Care Med 2004;169:479-87.

10. Cantin AM, North SL, Hubbard RC, et al. Normal alveolar epithelial lining fluid contains high levels of glutathione. J Appl Physiol 1987;63:152-7.

11. Garte S, Gaspari L, Alexandrie AK, et al. Metabolic gene polymorphism frequencies in control populations. Cancer Epidemiol Biomarkers Prev 2001;10:1239-48.

12. Bolt HM, Thier R. Relevance of the deletion polymorphisms of the glutathione S-transferases GSTT1 and GSTM1 in pharmacology and toxicology. Curr Drug Metab 2006; 7:613-28.

13. Anttila S, Hirvonen $A$, Vainio $\mathrm{H}$, et al. Immunohistochemical localization of glutathione S-transferases in human lung. Cancer Res 1993;53:5643-8.

14. Watson MA, Stewart RK, Smith GB, et al. Human glutathione S-transferase P1 polymorphisms: relationship to lung tissue enzyme activity and population frequency distribution. Carcinogenesis 1998;19:275-80.

15. Tamer L, Calikoglu M, Ates NA, et al. Glutathione-S-transferase gene polymorphisms (GSTT1, GSTM1, GSTP1) as increased risk factors for asthma. Respirology 2004;9:493-8.

16. Fryer AA, Bianco A, Hepple M, et al. Polymorphism at the glutathione S-transferase GSTP1 locus. A new marker for bronchial hyperresponsiveness and asthma. Am J Respir Crit Care Med 2000;161:1437-42.

17. Brasch-Andersen C, Christiansen L, Tan Q, et al. Possible gene dosage effect of glutathione-S-transferases on atopic asthma: using real-time PCR for quantification of GSTM1 and GSTT1 gene copy numbers. Hum Mutat 2004;24:208-14. 
18. Nickel R, Haider A, Sengler C, et al. Association study of glutathione S-transferase P1 (GSTP1) with asthma and bronchial hyper-responsiveness in two German pediatric populations. Pediatr Allergy Immunol 2005;16:539-41.

19. Carroll WD, Lenney W, Jones PW, et al. Effects of glutathione S-transferase M1, T1 and $\mathrm{P} 1$ on lung function in asthmatic families. Clin Exp Allergy 2005;35:1155-61.

20. Gilliland FD, Gauderman WJ, Vora H, et al. Effects of glutathione-S-transferase M1, $\mathrm{T1}$, and P1 on childhood lung function growth. Am J Respir Crit Care Med 2002;166:710-16

21. Rangasamy T, Cho CY, Thimmulappa RK, et al. Genetic ablation of Nrf2 enhances susceptibility to cigarette smoke-induced emphysema in mice. J Clin Invest 2004;114:1248-59.

22. Rangasamy T, Guo J, Mitzner WA, et al. Disruption of Nrf2 enhances susceptibility to severe airway inflammation and asthma in mice. J Exp Med 2005;202:47-59.

23. Kabesch M, Hoefler C, Carr D, et al. Glutathione $\mathbf{S}$ transferase deficiency and passive smoking increase childhood asthma. Thorax 2004:59:569-73.

24. Gilliland FD, Li YF, Dubeau L, et al. Effects of glutathione S-transferase M1, maternal smoking during pregnancy, and environmental tobacco smoke on asthma and wheezing in children. Am J Respir Crit Care Med 2002;166:457-63.

25. Murdzoska J, Devadason SG, Khoo SK, et al. In utero smoke exposure and role of maternal and infant glutathione s-transferase genes on airway responsiveness and lung function in infancy. Am J Respir Crit Care Med 2010;181:64-71.

26. Golding J, Pembrey M, Jones R. ALSPAC-the Avon Longitudinal Study of Parents and Children. I. Study methodology. Paediatr Perinat Epidemiol 2001:15:74-87.

27. Chinn S, Rona RJ. Height and age adjustment for cross sectional studies of lung function in children aged 6-11 years. Thorax 1992;47:707-14.

28. Rose-Zerilli MJ, Barton SJ, Henderson AJ, et al. Copy-number variation genotyping of GSTT1 and GSTM1 gene deletions by real-time PCR. Clin Chem 2009;55:1680-5.

29. Lu B, Zanutto E, Hornik R, et al. Matching with doses in an observational study of a media campaign against drug abuse. J Am Stat Assoc 2001;96:1245-53.

30. Olson JM. Testing the Hardy-Weinberg law across strata. Ann Hum Genet 1993:57:291-5

31. Gergen PJ, Fowler JA, Maurer KR, et al. The burden of environmental tobacco smoke exposure on the respiratory health of children 2 months through 5 years of age in the United States: Third National Health and Nutrition Examination Survey, 1988 to 1994. Pediatrics 1998;101:E8.

32. Obwegeser $\mathbf{R}$, Oguogho A, Ulm M, et al. Maternal cigarette smoking increases F2-isoprostanes and reduces prostacyclin and nitric oxide in umbilical vessels. Prostaglandins Other Lipid Mediat 1999:57:269-79.
33. Park EY, Hong YC, Lee $\mathrm{KH}$, et al. Maternal exposure to environmental tobacco smoke, GSTM1/T1 polymorphisms and oxidative stress. Reprod Toxicol 2008;26:197-202.

34. Li N, Nel AE. Role of the Nrf2-mediated signaling pathway as a negative regulator of inflammation: implications for the impact of particulate pollutants on asthma. Antioxid Redox Signal 2006;8:88-98.

35. Hayes JD, Flanagan JU, Jowsey IR. Glutathione transferases. Annu Rev Pharmacol Toxicol 2005:45:51-88.

36. Barnett BE, Hanna B, Parker G. Life event scales for obstetric groups. J Psychosom Res 1983:27:313-20.

37. Minelli C, Granell R, Newson R, et al. Glutathione-S-transferase genes and asthma phenotypes: a Human Genome Epidemiology (HuGE) systematic review and metaanalysis including unpublished data. Int J Epidemiol 2010;39:539-62.

38. Romieu I, Ramirez-Aguilar M, Sienra-Monge JJ, et al. GSTM1 and GSTP1 and respiratory health in asthmatic children exposed to ozone. Eur Respir $J$ 2006:28:953-9.

39. Islam T, Berhane K, McConnell R, et al. Glutathione-S-transferase (GST) P1, GSTM1 exercise, ozone and asthma incidence in school children. Thorax 2009;64:197-202.

40. Li YF, Gauderman WJ, Conti DV, et al. Glutathione S-transferase P1, maternal smoking, and asthma in children: a haplotype-based analysis. Environ Health Perspect 2008:116:409-15.

41. Gilliland FD, Rappaport EB, Berhane K, et al. Effects of glutathione S-transferase P1 M1, and T1 on acute respiratory illness in school children. Am J Respir Crit Care Med 2002:166:346-51.

42. Carroll WD, Lenney W, Child F, et al. Maternal glutathione S-transferase GSTP1 genotype is a specific predictor of phenotype in children with asthma. Pediatr Allergy Immunol 2005:16:32-9.

43. Grazuleviciene R, Danileviciute A, Nadisauskiene R, et al. Maternal smoking, GSTM1 and GSTT1 polymorphism and susceptibility to adverse pregnancy outcomes. Int J Environ Res Public Health 2009;6:1282-97.

44. Tunstall-Pedoe $\mathbf{H}$, Brown CA, Woodward M, et al. Passive smoking by self report and serum cotinine and the prevalence of respiratory and coronary heart disease in the Scottish Heart Health Study. J Epidemiol Community Health 1995:49:139-43

45. Bouzigon $\mathbf{E}$, Corda $\mathrm{E}$, Aschard $\mathrm{H}$, et al. Effect of 17q21 variants and smoking exposure in early-onset asthma. N Engl J Med 2008;359:1985-94.

46. Reijmerink NE, Kerkhof M, Koppelman GH, et al. Smoke exposure interacts with ADAM33 polymorphisms in the development of lung function and hyperresponsiveness. Allergy 2009;64:898-904. 